\title{
Association between Chronic Pain and Physical Frailty in Community-Dwelling Older Adults
}

\author{
Yuki Nakai ${ }^{1,2}$ (), Hyuma Makizako ${ }^{1, *}$, Ryoji Kiyama ${ }^{1}$, Kazutoshi Tomioka ${ }^{2}$, \\ Yoshiaki Taniguchi ${ }^{2}$, Takuro Kubozono ${ }^{3}$, Toshihiro Takenaka ${ }^{4}$ and Mitsuru Ohishi ${ }^{3}$ \\ 1 Department of Physical Therapy, School of Health Sciences, Faculty of Medicine, Kagoshima University, \\ Kagoshima 890-8544, Japan; nakai@health.nop.kagoshima-u.ac.jp (Y.N.); \\ kiyama@health.nop.kagoshima-u.ac.jp (R.K.) \\ 2 Graduate School of Health Sciences, Kagoshima University, Kagoshima 890-8544, Japan; \\ reha_tommy@yahoo.co.jp (K.T.); p.taniguchi0601@gmail.com (Y.T.) \\ 3 Department of Cardiovascular Medicine and Hypertension, Graduate School of Medical and Dental \\ Sciences, Kagoshima University, Kagoshima 890-0075, Japan; kubozono@cepp.ne.jp (T.K.); \\ ohishi@m2.kufm.kagoshima-u.ac.jp (M.O.) \\ 4 Tarumizu Municipal Medical Center, Tarumizu Chuo Hospital, Kagoshima 891-2124, Japan; \\ takenaka@tarumizumh.jp \\ * Correspondence: makizako@health.nop.kagoshima-u.ac.jp; Tel.: +81-99-275-5111
}

Received: 6 March 2019; Accepted: 10 April 2019; Published: 13 April 2019

\begin{abstract}
This cross-sectional study investigated the association between chronic pain and physical frailty in community-dwelling older adults. We analyzed data obtained from 323 older adults (women: $74.6 \%$ ) who participated in a community-based health check survey (the Tarumizu Study, 2017). Physical frailty was defined in terms of five parameters (exhaustion, slowness, weakness, low physical activity, and weight loss). We assessed the prevalence of chronic low back and knee pain using questionnaires. Participants whose pain had lasted $\geq$ two months were considered to have chronic pain. Among all participants, 138 (42.7\%) had chronic pain, and 171 (53.0\%) were categorized as having physical frailty or pre-frailty. Logistic regression analysis showed that chronic pain was significantly associated with the group combining frailty and pre-frailty (odds ratio 1.68, $95 \%$ confidence interval 1.03-2.76, $p=0.040$ ) after adjustment for age, sex, body mass index, score on the 15-item Geriatric Depression Scale, and medications. Comparing the proportions of chronic pain among participants who responded to the sub-items, exhaustion (yes: 65.9\%, no: 39.4\%) demonstrated a significant association $(p<0.001)$. Chronic pain could be associated with the group combining frailty and pre-frailty and is particularly associated with exhaustion in community-dwelling older adults. Therefore, there is a need for early intervention and consideration of the role of exhaustion when devising interventions for physical frailty in older individuals with chronic pain.
\end{abstract}

Keywords: physical frailty; chronic pain; older individuals

\section{Introduction}

Frailty is a decline in physiological ability with aging [1]. Cellular defects accumulate with age, creating a variety of disorders, including the loss of functional capacity [2]. Determinants of frailty can be considered according to domains (physical, psychological, and social) [3]. Frailty has multidimensional aspects, but its functional aspects are especially important in order to understand it [4]. Older individuals with frailty have an increased risk of negative health outcomes, such as falling, various disabilities, a lower quality of life, hospitalization, and mortality [1,5-8]. Therefore, early identification and assessment of community-dwelling older individuals with frailty is required to prevent progression to negative health states in an aging society. 
In a growing number of older adults, there is a heavy comorbidity burden and a high rate of geriatric syndromes including chronic pain [9]. Chronic pain, which causes a rise in healthcare costs and a deterioration in the quality of life, is a common symptom among community-dwelling older adults [9-11]. Epidemiological studies reveal that the prevalence of chronic pain is high in community-dwelling older adults $[10,11]$. For example, Liberman et al. reported a high rate of chronic pain $(55.2 \%)$ and geriatric syndromes $(85.4 \%)$ as well as an association between them [9]. Previous studies have also reported an association between chronic pain and limitations in the activities of daily living $[12,13]$ because of deterioration in physical functioning [12,14], poor psychological status $[15,16]$, and low physical activity levels $[17,18]$. Therefore, it is imperative to identify older adults with chronic pain earlier and develop a means of preventing chronic pain in community-dwelling older adults.

It is known that chronic pain among community-dwelling older adults is a risk factor for worsening frailty [19]. However, the relationships between the early stages of physical frailty and chronic pain and the sub-items of physical frailty and chronic pain in older adults remain unclear.

Examining the cross-sectional relationship between physical frailty and chronic pain may provide information that could be helpful in developing more effective strategies to prevent frailty from a multidimensional perspective. In this study, we examined the effect of chronic pain as a risk factor for the potential development of physical frailty, and investigated which components of frailty are more relevant to chronic pain among community-dwelling older adults.

\section{Materials and Methods}

\subsection{Participants}

The current cross-sectional study used data from the Tarumizu Study 2017. Details of this study have been reported previously [20]. Briefly, the Tarumizu Study 2017, which involved collaboration between Kagoshima University (Faculty of Medicine), the Tarumizu city office, and Tarumizu Chuo Hospital, was conducted in November and December 2017 as a community-based health check survey. The participants of this study were selected from about 3810 older people over the age of 65 living in Tarumizu, a city in Kagoshima Prefecture, Japan. They were recruited through local newspaper advertisements and community campaigns. This was a health survey that is essentially based on the city's health examination; the criterion for inclusion was being able to walk on one's own, while the criterion for exclusion was having already received certification for long-term care. Informed consent was obtained from all participants prior to their inclusion in the study, and the Ethics Committee of the Faculty of Medicine, Kagoshima University approved the study protocol (Ref. No. 170103).

\subsection{Physical Frailty}

The status of physical frailty was based on the consisting of five components: exhaustion, slowness, muscle weakness, low physical activity, and weight loss [1]. Exhaustion was defined when answering "yes" to the next question from Kihon Checklist which is a self health checklist developed by the Japanese Ministry of Health, Labor and Welfare [21]: "Have you ever felt tired for no reason in the last two weeks?" Slowness was defined using $(<1.0 \mathrm{~m} / \mathrm{s})$ as the normal walking speed cutoff value [22]. Weakness was defined using the maximum grip strength by different sex cutoff values $(<26 \mathrm{~kg}$ for men, $<18 \mathrm{~kg}$ for women) [23]. Low physical activity level was defined by the following questions: (1) “Do you do light exercise or sports for your health?" and (2) "Do you regularly exercise or sport?" "No" participants in both questions were categorized into low activity levels [24]. Weight loss was evaluated if participants answered "yes" to the following question, "Have you lost more than $2 \mathrm{~kg}$ in the past six months?" [21]. Participants who did not have any of these characteristics were not physically frail; physically pre-frail had one or two characteristics; and physically frail had three or more characteristics $[25,26]$. 


\subsection{Chronic Pain}

In this study, low back pain and knee pain were defined as chronic pain. These are the leading causes of pain complaints due to functional limitations and disorders in the elderly in Japan and other countries $[27,28]$. We assessed chronic pain by a face-to-face interview using the following four questions: "Do you have low back pain at the present time?" (yes), "Has that pain endured more than two months?" (yes), "Do you have knee pain at the present time?" (yes), and "Has that pain endured more than two months?" (yes) $[19,29,30]$. Participants with either low back or knee pain, or both lasting more than two months, formed the chronic pain group; those with neither low back nor knee pain formed the non-pain group; and those with low back or knee pain for less than two months formed the acute pain group.

\subsection{Covariates}

Age (years), sex, body mass index (BMI), responses on the 15-item Geriatric Depression Scale (GDS-15) [24], and total medications used (number/day) were assessed and included as covariates. Regarding these conditions and medications, doctors and nurses interviewed directly.

\subsection{Statistical Analysis}

The Mantel-Haenszel tests were used to compare the trends in sex and chronic pain in the groups formed on the basis of physical frailty status (non-physically frail, pre-frail, and frail). A one-way analysis of variance for continuous measures was performed to assess differences among frailty status groups in age, BMI, GDS-15 scores, and the total number of prescribed medications.

The association between physical frailty and the prevalence of chronic pain was examined using multivariate logistic regression analyses. Dependent variables were classified into two patterns: the group combining physical frailty and pre-frailty, or physical frailty alone. The model in the multivariate logistic regression analysis was adjusted for age, sex, BMI, GDS-15 score, and the number of prescribed medications as covariates. The adjusted odds ratios (ORs) for incidents related to physical frailty were estimated with $95 \%$ confidence intervals (95\% CIs). The comparisons of the prevalence of physical frailty sub-items in participants and of their chronic pain were made using chi-square tests. All analyses were conducted using IBM SPSS Statistics 25.0 (IBM Japan, Tokyo, Japan). The level of statistical significance was set at $p<0.05$.

\section{Results}

\subsection{Subsection Characteristics of Participants}

A total of 452 older individuals were enrolled in the Tarumizu Study 2017; 380 of them participated in a health check survey. The data from these 380 participants was eligible for the current investigation. In this study, participants aged under 65 years $(n=1$, the survey was undertaken before the participant's 65th birthday), with a history of diagnosis of dementia $(n=7)$, missing data on physical frailty assessments $(n=2)$, no response to questions on pain $(n=1)$, and grip strength measures for those with unsafe conditions (e.g., systolic blood pressure $\geq 180 \mathrm{mmHg}$ ) were excluded $(n=5)$. Participants with acute pain were also excluded $(n=41)$. Finally, data from 323 community-dwelling older adults (aged $\geq 65$ years, mean age: 75.2 years, women: 74.6\%) were analyzed (Figure 1). 


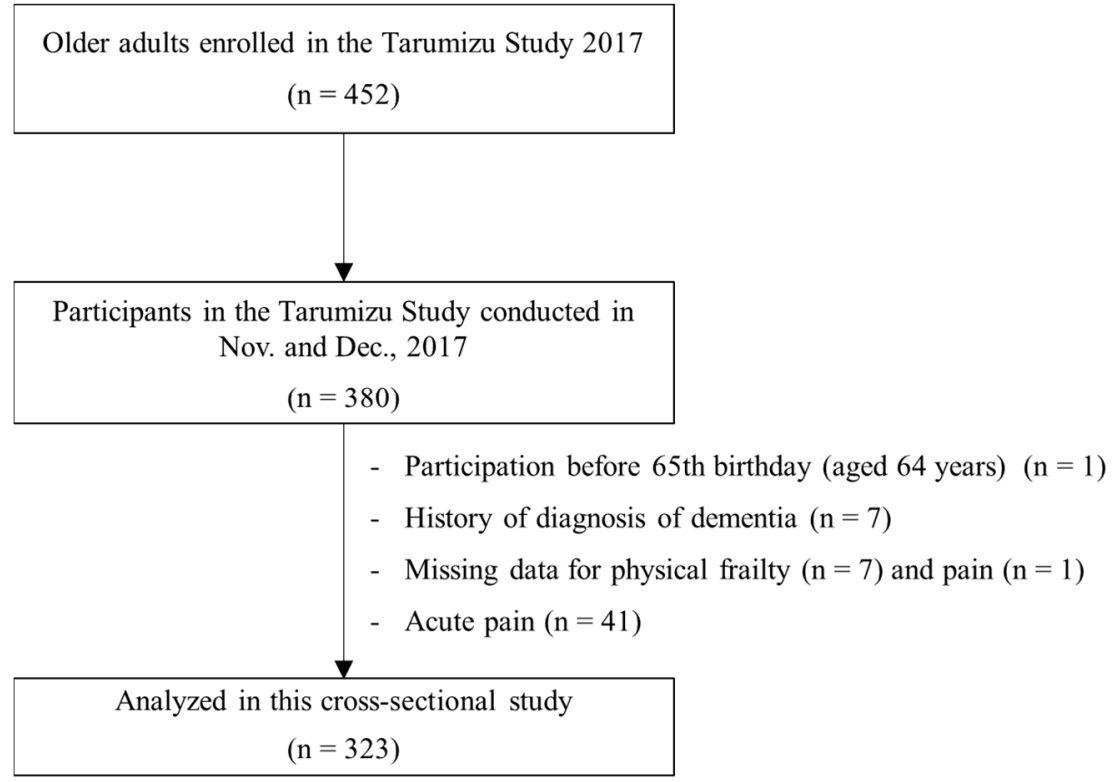

Figure 1. Participant inclusion criteria flow diagram.

The characteristics of the participants and the comparisons among groups divided by frailty status are described in Table 1. Out of 323 participants, 152 (47.1\%) were considered physically non-frail, $152(47.1 \%)$ were considered physically pre-frail, 19 (5.9\%) were considered physically frail, and 138 $(42.7 \%)$ met the criteria for chronic pain. Of the 152 non-frail participants, 52 (34.2\%) had chronic pain; of the 152 pre-frail participants, $76(50.0 \%)$ had chronic pain; and of the 19 frail participants, $10(52.6 \%)$ had chronic pain. Regarding frailty status, there was a significant difference in chronic pain $(p=0.014)$. There were significant differences in certain characteristics of frailty status, such as age $(p<0.001)$, GDS-15 score $(p<0.001)$, and prescribed medications $(p=0.001)$, but no significant differences in BMI $(p=0.924)$ and $\operatorname{sex}(p=0.226)$.

Table 1. Characteristics of the participants (mean \pm SD or \%).

\begin{tabular}{lccccc}
\hline \multicolumn{1}{c}{ Variable } & Total & Non-Frailty & Pre-Frailty & Frailty & \multirow{2}{*}{$\boldsymbol{p}^{*}$} \\
\cline { 2 - 5 } & $\mathbf{( n = 3 2 3 )}$ & $\mathbf{( n = 1 5 2 )}$ & $\mathbf{( n = 1 5 2 )}$ & $\boldsymbol{( n = 1 9 )}$ & \\
\hline Chronic pain, n (\%) & $138(42.7)$ & $52(34.2)$ & $76(50.0)$ & $10(52.6)$ & 0.014 \\
Age, mean \pm SD (years) & $75.2 \pm 6.5$ & $74.1 \pm 5.8$ & $75.4 \pm 6.7$ & $81.9 \pm 7.1$ & $<0.001$ \\
Women, n (\%) & $241(74.6)$ & $115(75.7)$ & $109(71.7)$ & $17(89.5)$ & 0.226 \\
BMI, mean \pm SD $\left(\mathrm{kg} / \mathrm{m}^{2}\right)$ & $23.5 \pm 3.4$ & $23.4 \pm 3.2$ & $23.5 \pm 3.5$ & $23.6 \pm 4.2$ & 0.924 \\
GDS-15 score mean \pm SD (points) & $2.5 \pm 2.5$ & $2.0 \pm 2.0$ & $2.8 \pm 2.5$ & $5.2 \pm 3.5$ & $<0.001$ \\
Medications mean \pm SD (number) & $3.7 \pm 3.9$ & $3.0 \pm 3.4$ & $4.1 \pm 4.0$ & $6.0 \pm 5.3$ & 0.001 \\
\hline SD, standard deviation; BMI, body mass index; GDS-15, 15-item version of the Geriatric Depression Scale. \\
* Mantel-Haenszel test for proportion trends and one-way analysis of variance for continuous measures.
\end{tabular}

\subsection{Associations of Prevalence of Chronic Pain and Physical Frailty}

The results of logistic regression analysis using a group combining frailty and pre-frailty participants as dependent variables are shown in the following Table 2. In the crude models, chronic pain was significantly associated with a group combining frailty and pre-frailty (OR 1.95, 95\% CI 1.24-3.05, $p=0.004)$. In the adjusted models, which included age, sex, BMI, GDS-15 score, and the number of prescribed medications as covariates, chronic pain (OR 1.68, 95\% CI 1.03-2.76, $p=0.040$ ) and GDS-15 score (OR 1.17, 95\% CI 1.06-1.30, $p=0.003$ ) was associated with a group combining frailty and pre-frailty. The results of logistic regression analysis using only the frailty group of participants as dependent variables are shown in the following. Chronic pain was not associated with only the 
frailty group in the crude models (OR 1.53, 95\% CI 0.60-3.87) but also in the adjusted models including covariates (OR 2.83, 95\% CI 0.79-10.21). Age (OR 1.22, 95\% CI 1.09-1.36, $p=0.001$ ), GDS-15 score (OR 1.50, 95\% CI 1.20-1.87, $p<0.001$ ), and the number of prescribed medications (OR 1.15, 95\% CI $1.00-1.32, p=0.047$ ) were associated only with the frailty group in the adjusted models.

Table 2. Logistic regression analysis between chronic pain and physical frailty status.

\begin{tabular}{|c|c|c|c|c|c|c|c|c|}
\hline \multirow{3}{*}{$\begin{array}{l}\text { Independent } \\
\text { Variable }\end{array}$} & \multicolumn{8}{|c|}{ Dependent Value: Classification of Two Patterns of Physical Frailty Prevalence Rates } \\
\hline & \multicolumn{4}{|c|}{ Non-Frailty \& Pre-Frailty vs Frailty } & \multicolumn{4}{|c|}{ Non-Frailty vs Pre-Frailty \& Frailty } \\
\hline & $\begin{array}{c}\text { Crude } \\
\text { OR }(95 \% \text { CI) }\end{array}$ & $p$ & $\begin{array}{c}\text { Adjusted } \\
\text { OR (95\% CI) }\end{array}$ & $p$ & $\begin{array}{c}\text { Crude } \\
\text { OR }(95 \% \mathrm{CI})\end{array}$ & $p$ & $\begin{array}{c}\text { Adjusted } \\
\text { OR (95\% CI) }\end{array}$ & $p$ \\
\hline Chronic pain & $1.53(0.60-3.87)$ & 0.371 & $2.83(0.79-10.21)$ & 0.112 & $1.95(1.24-3.05)$ & $0.004 * *$ & $1.68(1.03-2.76)$ & 0.040 * \\
\hline Age & & & $1.22(1.09-1.36)$ & $0.001 * *$ & & & $1.03(0.99-1.07)$ & 0.176 \\
\hline Women & & & $2.15(0.42-10.90)$ & 0.358 & & & $0.80(0.47-1.38)$ & 0.428 \\
\hline BMI & & & $1.21(1.00-1.46)$ & 0.058 & & & $1.00(0.94-1.08)$ & 0.938 \\
\hline GDS-15 & & & $1.50(1.20-1.87)$ & $<0.001^{* *}$ & & & $1.17(1.06-1.30)$ & $0.003^{* *}$ \\
\hline Medications & & & $1.15(1.00-1.32)$ & 0.047 * & & & $1.06(1.00-1.14)$ & 0.069 \\
\hline
\end{tabular}

Note: OR, odds ratio; CI, confidence interval; BMI, body mass index; GDS-15, 15-item version of the Geriatric Depression Scale; the bold typeface indicates statistical significance; ${ }^{* *} p<0.01 ;{ }^{*} p<0.05$; adjusted for age, sex, BMI, GDS-15 score, and number of medications.

Analysis of the prevalence of chronic pain in participants corresponding to the sub-items that determine frailty is represented in Figure 2. Exhaustion (yes: 65.9\%, no: 39.4\%) was significantly associated with the prevalence of chronic pain $(p<0.001)$. Slowness (yes: $52.4 \%$, no: $42.1 \%$ ), weakness (yes: 50.0\%, no: 40.2\%), low activity (yes: $44.6 \%$, no: $42.3 \%$ ), and weight loss (yes: $51.1 \%$, no: $41.4 \%$ ) were not significantly associated with the prevalence of chronic pain.

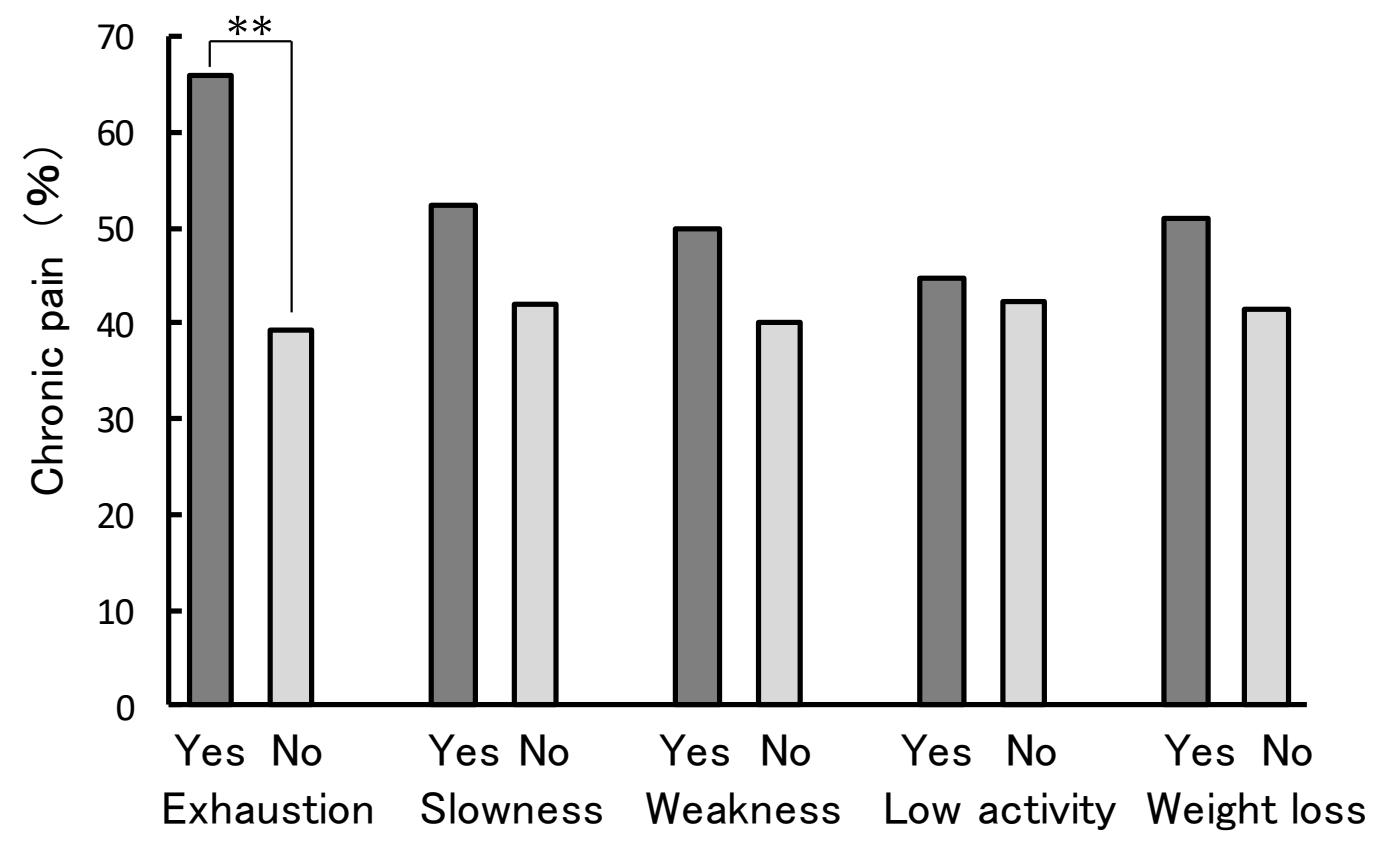

Figure 2. Association of the sub-items of physical frailty and presence of chronic pain. $\chi^{2}$ test for proportions; ${ }^{* *} p<0.01$.

\section{Discussion}

This cross-sectional study indicated that chronic pain in community-dwelling older adults could be associated with the group combining frailty and pre-frailty. That group was associated with chronic pain even after the adjustment for potential covariates. Also, participants with exhaustion had a significantly higher proportion of chronic pain. 
The development of an effective prevention strategy for frailty in community-dwelling older adults is a pressing issue in a rapidly-aging society (e.g., Japan), as frailty has a negative effect on health [1]. Chronic pain among community-dwelling older adults is a risk factor for worsening frailty [19]. The prevalence of chronic pain in this study was almost the same as in a previous study investigating Japanese adults [29], which reported that 1032 (39.3\%) adults (mean age 57.7 years) out of 2628 sampled had chronic pain. Makizako et al. investigated community-dwelling older adults using the same definition of physical frailty as used in the present study, and reported that $56.5 \%$ of older adults were frail or pre-frail [26]. Therefore, the present findings are consistent with previous results, and are therefore credible. The previously mentioned prospective cohort study reported that physical frailty, and even being pre-frail, strongly predicts an increased risk of disability in Japanese older adults [26]. In the present study, the presence of chronic pain in the physically frail or pre-frail groups was significantly higher than in the non-frail group. This may be explained by the fact that chronic pain has profound effects on a number of health outcomes [31]. Chronic pain is associated with and may be the origin of various health hazards, including depression and comorbidities that exacerbate physical frailty. Also, in this study, an association between frailty and depression is suggested. Thus, our findings suggest that interventions in chronic pain in the early stages of physical frailty (mostly pre-frail status) may have something to do with preventing the risk of developing disability in community-dwelling older adults.

Analysis of the prevalence of chronic pain and sub-items of frailty showed that exhaustion, not other sub-items, was significantly associated with chronic pain. Many previous studies have reported on the relationship between pain and physical function deterioration $[12,14,32,33]$. However, in the present study, chronic pain was associated with exhaustion rather than with physical function. Shega et al. [31] argued that older adults with persistent pain, lack of sleep, and poor nutrition may experience a decrease in their physiological reserves, which increases the likelihood of falls and cognitive dysfunction. Exhaustion may be related to sleep deprivation and nutritional status. This may cause mental distress and also lose confidence. Then, they may express feelings that they cannot fulfill their social roles sufficiently with families, friends and neighbors. This could lead to withdrawal indoors and lead to a decline in physical activity as well. This suggests that in older adults, pre-frailty or frailty is initially associated with exhaustion, and subsequently perhaps with a decline in physical function. Among older adults, it is plausible that the multidimensional nature of chronic pain has an impact on one's physiological systems, reduces one's physiological reserves, and decreases one's ability to maintain homeostasis [34]. Thus, there is a need for early intervention and consideration of the role of exhaustion when devising interventions for physical frailty in older adults with chronic pain.

This study includes several limitations. First, while chronic pain was recognized as an important aspect of physical frailty, the roles of the cognitive and psychological domains were not considered. Also, other potential covariates, such as lifestyle, nutritional, and hormonal factors [35-37], that could be related to exhaustion, were not considered. Second, we studied the relationship between chronic pain and the prevalence of frailty using cross-sectional design, but statistical power was insufficient due to the small number of participants. We need more prospective study with more participants. Additionally, regarding the definition of pain, we asked questions about low back and knee pain, but did not consider the degree of pain. The prevalence of low back and knee pain is high in Japan and other countries [27,28], but other parts of the body and different degrees of pain may need to be considered. We also need to consider other chronic pain cut-offs. In this study, registered 452 older adults accounted for about $10 \%$ of the surveyed subjects in the city. Moreover, they were not randomly selected. In this field, conducting longitudinal studies would accumulate valuable evidence.

\section{Conclusions}

Community-dwelling older adults with chronic pain were associated with the group combining physical frailty and pre-frailty. In particular, exhaustion may be associated with the prevalence of chronic pain. The maintenance of a patient's physically non-frail status through interventions accounting for 
exhaustion can be a strategy for the maintenance of physical function among community-dwelling older adults with chronic pain.

Author Contributions: Y.N. was responsible for study conceptualization and design, analysis and interpretation of data, and writing the manuscript. H.M. contributed to study conceptualization and design, subject recruitment, interpretation of data, and writing the manuscript. R.K., K.T., and Y.T. were instrumental in acquiring data and preparing the manuscript. T.K., T.T. and M.O. helped with recruitment, interpreting the data, and preparing the manuscript. All authors were involved in designing the study; all contributed to and approved the final manuscript.

Funding: This work was supported by AMED under Grant Number JP18dk0207027; Research Funding for Longevity Sciences (29-42) from the National Center for Geriatrics and Gerontology (NCGG) and JSPS KAKENHI (Grant-in-Aid for challenging Exploratory Research) Grant Number JP17K19870.

Acknowledgments: The authors thank Tarumizu Chuo Hospital for helping with arranging testers, medical doctors, nurses, physical therapists, occupational therapists, and instructors. We also thank the Tarumizu city office for its contributions to the study. Our sincere thanks goes out to all the participants in the study.

Conflicts of Interest: The authors declare no conflict of interest.

\section{References}

1. Fried, L.P. Frailty in Older Adults: Evidence for a Phenotype. J. Gerontol. Biol. Sci. Med. Sci. 2001, 56, $146-156$. [CrossRef]

2. Mitnitski, A.; Collerton, J.; Martin-Ruiz, C.; Jagger, C.; von Zglinicki, T.; Rockwood, K.; Kirkwood, T.B.L. Age-related frailty and its association with biological markers of ageing. BMC Med. 2015, 13, 1-9. [CrossRef] [PubMed]

3. Schols, J.M.G.A.; Gobbens, R.J.J.; van Assen, M.A.L.M.; Luijkx, K.G.; Wijnen-Sponselee, M.T. Determinants of Frailty. J. Am. Med. Dir. Assoc. 2010, 11, 356-364.

4. Bernabei, R.; Marzetti, E.; Albaina, O.; Junius-Walker, U.; Wiese, B.; Soleymani, D.; Onder, G. The essence of frailty: A systematic review and qualitative synthesis on frailty concepts and definitions. Eur. J. Intern. Med. 2018, 56, 3-10.

5. Tom, S.E.; Adachi, J.D.; Anderson, F.A.; Boonen, S.; Chapurlat, R.D.; Compston, J.E.; Cooper, C.; Gehlbach, S.H.; Greenspan, S.L.; Hooven, F.H.; et al. Frailty and fracture, disability, and falls: A multiple country study from the global longitudinal study of osteoporosis in women. J. Am. Geriatr. Soc. 2013, 61, 327-334. [CrossRef] [PubMed]

6. Garre-Olmo, J.; Calvó-Perxas, L.; López-Pousa, S.; De Gracia Blanco, M.; Vilalta-Franch, J. Prevalence of frailty phenotypes and risk of mortality in a community-dwelling elderly cohort. Age Ageing 2013, 42, 46-51. [CrossRef] [PubMed]

7. Kojima, G.; Iliffe, S.; Jivraj, S.; Walters, K. Association between frailty and quality of life among communitydwelling older people: A systematic review and meta-analysis. J. Epidemiol. Community Health 2016, 70, 716-721. [CrossRef]

8. Vermeiren, S.; Vella-Azzopardi, R.; Beckwée, D.; Habbig, A.K.; Scafoglieri, A.; Jansen, B.; Bautmans, I.; Bautmans, I.; Verté, D.; Beyer, I.; et al. Frailty and the Prediction of Negative Health Outcomes: A Meta-Analysis. J. Am. Med. Dir. Assoc. 2016, 17, 1163.e1-1163.e17. [CrossRef] [PubMed]

9. Peleg, R.; Press, Y.; Freud, T.; Liberman, O.; Keren, A. Chronic pain and geriatric syndromes in community-dwelling patients aged $\geq 65$ years. J. Pain Res. 2018, 11, 1171-1180.

10. Nakamura, M.; Nishiwaki, Y.; Ushida, T.; Toyama, Y. Prevalence and characteristics of chronic musculoskeletal pain in Japan. J. Orthop. Sci. 2011, 16, 424-432. [CrossRef] [PubMed]

11. Hasegawa, M.; Yamazaki, S.; Kimura, M.; Nakano, K.; Yasumura, S. Community-based exercise program reduces chronic knee pain in elderly Japanese women at high risk of requiring long-term care: A non-randomized controlled trial. Geriatr. Gerontol. Int. 2013, 13, 167-174. [CrossRef]

12. Eggermont, L.H.P.; Penninx, B.W.J.H.; Jones, R.N.; Leveille, S.G. Depressive symptoms, chronic pain, and falls in older community-dwelling adults: The mobilize Boston study. J. Am. Geriatr. Soc. 2012, 60, $230-237$. [CrossRef]

13. Buchman, A.S.; Shah, R.C.; Leurgans, S.E.; Boyle, P.A.; Wilson, R.S.; Bennett, D.A. Musculoskeletal pain and incident disability in community-dwelling older adults. Arthritis Care Res. 2010, 62, 1287-1293. [CrossRef] 
14. Park, J.; Hughes, A.K. Nonpharmacological approaches to the management of chronic pain in communitydwelling older adults: A review of empirical evidence. J. Am. Geriatr. Soc. 2012, 60, 555-568. [CrossRef]

15. Lihavainen, K.; Sipilä, S.; Rantanen, T.; Sihvonen, S.; Sulkava, R.; Hartikainen, S. Contribution of musculoskeletal pain to postural balance in community-dwelling people aged 75 years and older. J. Gerontol. Ser. Biol. Sci. Med. Sci. 2010, 65A, 990-996. [CrossRef] [PubMed]

16. Onder, G.; Landi, F.; Gambassi, G.; Liperoti, R.; Soldato, M.; Catananti, C.; Finne-Soveri, H.; Katona, C.; Carpenter, I.; Bernabei, R. Association between pain and depression among older adults in Europe: Results from the Aged in Home Care (AdHOC) project: A cross-sectional Study. J. Clin. Psych. 2005, 66, 982-988. [CrossRef]

17. Eggermont, L.H.P.; Leveille, S.G.; Shi, L.; Kiely, D.K.; Shmerling, R.H.; Jones, R.N.; Guralnik, J.M.; Bean, J.F. Pain characteristics associated with the onset of disability in older adults: The maintenance of balance, independent living, intellect, and zest in the elderly boston study. J. Am. Geriatr. Soc. 2014, 62, 1007-1016. [CrossRef]

18. Plooij, B.; Scherder, E.J.A.; Eggermont, L.H.P. Physical inactivity in aging and dementia: A review of its relationship to pain. J. Clin. Nurs. 2012, 21, 3002-3008. [CrossRef]

19. McGreevy, K.; Bottros, M.M.; Raja, S.N. Preventing chronic pain following acute pain: Risk factors, preventive strategies, and their efficacy. Eur. J. Pain Suppl. 2011, 5, 365-376. [CrossRef]

20. Makizako, H.; Kubozono, T.; Kiyama, R.; Takenaka, T.; Kuwahata, S.; Tabira, T.; Kanoya, T.; Horinouchi, K.; Shimada, H.; Ohishi, M. Associations of social frailty with loss of muscle mass and muscle weakness among community-dwelling older adults. Geriatr. Gerontol. Int. 2019, 19, 76-80. [CrossRef] [PubMed]

21. Fukutomi, E.; Okumiya, K.; Wada, T.; Sakamoto, R.; Ishimoto, Y.; Kimura, Y.; Chen, W.L.; Imai, H.; Kasahara, Y.; Fujisawa, M.; et al. Relationships between each category of 25-item frailty risk assessment (Kihon Checklist) and newly certified older adults under Long-Term Care Insurance: A 24-month follow-up study in a rural community in Japan. Geriatr. Gerontol. Int. 2015, 15, 864-871. [CrossRef] [PubMed]

22. Salpakoski, A.; Portegijs, E.; Kallinen, M.; Sihvonen, S.; Kiviranta, I.; Alen, M.; Rantanen, T.; Sipil, S. Physical inactivity and pain in older men and women with hip fracture history. Gerontology 2010, 57, 19-27. [CrossRef]

23. Wade, K.F.; Lee, D.M.; Mcbeth, J.; Ravindrarajah, R.; Gielen, E.; Pye, S.R.; Vanderschueren, D.; Pendleton, N.; Finn, J.D.; Bartfai, G.; et al. Chronic widespread pain is associated with worsening frailty in European men. Age Ageing 2016, 45, 268-274. [CrossRef]

24. Shimada, H.; Makizako, H.; Doi, T.; Yoshida, D.; Tsutsumimoto, K.; Anan, Y.; Uemura, K.; Ito, T.; Lee, S.; Park, H.; et al. Combined Prevalence of Frailty and Mild Cognitive Impairment in a Population ofElderly Japanese People. J. Am. Med. Dir. Assoc. 2013, 14, 518-524. [CrossRef]

25. Makizako, H.; Tsutsumimoto, K.; Nakakubo, S.; Hotta, R.; Makino, K.; Shimada, H.; Doi, T.; Lee, S. Social Frailty Leads to the Development of Physical Frailty among Physically Non-Frail Adults: A Four-Year Follow-Up Longitudinal Cohort Study. Int. J. Environ. Res. Pub. Health 2018, 15, 490. [CrossRef]

26. Makizako, H.; Shimada, H.; Doi, T.; Tsutsumimoto, K.; Suzuki, T. Impact of physical frailty on disability in community-dwelling older adults: A prospective cohort study. BMJ Open 2015, 5, 1-9. [CrossRef]

27. Hirase, T.; Kataoka, H.; Inokuchi, S.; Nakano, J.; Sakamoto, J.; Okita, M. Factors associated with chronic musculoskeletal pain in Japanese community-dwelling older adults. Medicine 2017, 96, e7069. [CrossRef]

28. Patel, K.V.; Guralnik, J.M.; Dansie, E.J.; Turk, D.C. Prevalence and impact of pain among older adults in the United States: Findings from the 2011 National Health and Aging Trends Study. Pain 2013, 154, 2649-2657. [CrossRef] [PubMed]

29. Knutson, G.A. Incidence of foot rotation, pelvic crest unleveling, and supine leg length alignment asymmetry and their relationship to self-reported back pain. J. Manipul. Physiol. Ther. 2002, 25, 110E. [CrossRef]

30. Hirase, T.; Kataoka, H.; Inokuchi, S.; Nakano, J.; Sakamoto, J.; Okita, M. Effects of exercise training combined with increased physical activity to prevent chronic pain in community-dwelling older adults: A preliminary randomized controlled trial. Pain Res. Manag. 2018, 2018, 1-7. [CrossRef] [PubMed]

31. Hunt, I.M.; Silman, A.J.; Benjamin, S.; McBeth, J.; Macfarlane, G.J. The prevalence and associated features of chronic widespread pain in the community using the "Manchester" definition of chronic widespread pain. Rheumatology 1999, 38, 275-279. [CrossRef]

32. Yesavage, J.A. Geriatric Depression Scale. Psychopharmacol. Bull. 1988, 24, 709-711. 
33. Inoue, S.; Kobayashi, F.; Nishihara, M.; Arai, Y.-C.P.; Ikemoto, T.; Kawai, T.; Inoue, M.; Hasegawa, T.; Ushida, T. Chronic Pain in the Japanese Community-Prevalence, Characteristics and Impact on Quality of Life. PLoS ONE 2015, 10, e0129262. [CrossRef]

34. Zhu, K.; Devine, A.; Dick, I.M.; Prince, R.L. Association of back pain frequency with mortality, coronary heart events, mobility, and quality of life in elderly women. Spine 2007, 32, 2012-2018. [CrossRef]

35. Isanejad, M.; Mursu, J.; Sirola, J.; Kröger, H.; Rikkonen, T.; Tuppurainen, M.; Erkkilä, A.T. Dietary protein intake is associated with better physical function and muscle strength among elderly women. Br. J. Nutr. 2016, 115, 1281-1291. [CrossRef]

36. Oliveira, M.R.; Fogaça, K.C.; Leandro-Merhi, V.A. Nutritional status and functional capacity of hospitalized elderly. Nutr. J. 2009, 8, 54. [CrossRef]

37. Frontera, W.R.; Ochala, J. Skeletal Muscle: A Brief Review of Structure and Function. Calcif. Tiss. Int. 2015, 96, 183-195. [CrossRef]

(C) 2019 by the authors. Licensee MDPI, Basel, Switzerland. This article is an open access article distributed under the terms and conditions of the Creative Commons Attribution (CC BY) license (http://creativecommons.org/licenses/by/4.0/). 